\title{
The Nature of Theory in Qualitative and Quantitative Research
}

\author{
Faiswal Kasirye \\ Department of Communication, \\ International Islamic University Malaysia \\ Email: Kasirye.faiswal@gmail.com
}

\section{INTRODUCTION}

In scientific terms, a theory is an explanation of a phenomenon using facts and hypothesized statements or assumptions that may predict the outcome of a research study. it is usually crafted in a scientific manner using scientific methods (Green, 2014). It can also be looked at as an essential tool used by researchers to explain the occurrence of issues in the society.

Saldaña and Omasta (2016) also define the theory as "social life issues that holds transferable applications to other settings, context, populations, and possibly time periods" (p. 257). In addition, this in real sense of it means that theories "predict actions through logic, explains how and why things happen, provides insights through social life and accounts for variation" (257). The theories do help mostly researchers in guiding them on what to do in their research studies. These can be either qualitative or quantitative studies in nature.

Theories are mostly invented and built to address questions relating to "why" things happen the way they do. For example, who do people use social media, why users use ecommerce instead of physical shopping, why are some people assume leadership and they succeed while other fail and so many other whys that are scientifically proven during a research process that is vigorously guided by the different theories. The predictions or hypothesized statements suggested by the theory are usually tested by the quantitative approaches (Ravitch \& Carl, 2016). The hypothesized statements can however be right or wrong and the only way to know that for sure is to measure them using quantitative statistical software.

In the following write up, we focus on the nature and behaviour of how the theory helps researchers accomplish their studies both qualitative and those which are quantitative in nature. 


\section{The Nature of Theory in Quantitative Studies}

Quantitative research are empirical studies that use statistical data to reach solve a problem at hand through a variety of methods that are used to gather responses from the participants. It is mandated to quantitatively develop and use theories to reach generalizable findings. Quantitatively, the theory will present variables that will be based on to conduct the study and test the theory basing on those particular variables but using statistical measures to either confirm or deny the hypothesized statements. It is important to note though that, in quantitative research, the theory performs a very important role of predicting how the results are going to turn out (Taormina, 2013).

The nature of theory in quantitative studies is based on the assumption that the theory assumes the framework and basis of guiding the entire process of research. Hypotheses made at the onset of the study are used to test the objectives of the study and questions but they too originate from the theory, and or, they must have a link on to them that is directly associated to the theory that is guiding the study at hand (Merriam \& Tisdell, 2016).

The hypotheses used in quantitative studies are usually derived from the main issue under investigation but directly through the variables that are extracted from the theory and presented through a conceptual framework and the previous literature cited in the study to support the assumption or predictions in the study. Creswell (2017) deduces that the researcher at the onset of the study is mandated to clearly define the variables in the study and make sure that while predicting the outcome of the study, the hypotheses are generated from the said variables that have been defined by the previous literature in the same field.

Furthermore, quantitatively, the variables in the theory are measured in statements that are usually formed or constructed using a questionnaire or other methods that are usually presented to the respondents to react on them and later find out through statistical software the attitudes and behaviour of the respondents while answering the questions in the questionnaire.

After the data is collected from the respondents, the researcher then uses numerical measurements to either confirm the hypothesized statements at the onset of the study, or deny them. In most cases, once the statements are supported, the theory is also performing its role of guiding the study because in every step of the research, it has been involved all the way up to the discussion of the 
findings to prove whether the statements are supported or rejected. All this is however done in a deductive way of doing research that deals with testing how the theory properly guides the phenomenon under study as advanced by Creswell (2011).

In a nutshell, quantitative studies construct statements in form of hypotheses and statistically analyses them to confirm or deny the theory used in the study.

\section{The Nature of Theory in Qualitative Studies}

In qualitative research theories relate to narratives, ethnography, phenomenology and other approaches in addition to other knowledge or epistemological approaches that are always abreast in guiding a particular study (Glesne, 2011). These methods are influenced by the various methodological approaches that are critical in choosing a particular theory to use in the study and or the entire theoretical framework. In addition, the concept of doing research in a qualitative approach rests primarily on the different concepts that are applied while choosing a theoretical framework and the researcher's knowledge to the phenomenon under study.

Also, qualitative studies using various qualitative methods may formulate models or theories at the end of the research unlike in the quantitative approaches (Maxwell, 2012). On this issue, some researchers like Saldaña (2014) argues that "theory construction should be the primary type of theoretical thought in qualitative research and urged researchers to consider utilizing the frameworks of noted theorists to guide qualitative studies" (p. 57). Epistemologically, other researchers also stress the issue of theory building in qualitative research approaches as "theoryladen" (Lincoln \& Guba, 1994) and observation statements (Flinders \& Mills, 1993).

Furthermore, Maxwell (2013) also looked at the qualitative conceptual framework as an alternative theory relating to the subject of investigation that constructs the design of the study, he noted that, "this may also be called the 'theoretical framework' or 'idea context' for the study" (p. 39). In addition, using theories help in taming goals, formulating research questions, choosing methodological approaches, identifying possible research threats to reliability validity, as well as highlighting the significance of the research. Maxwell (2012) adds that, the primary source of the conceptual framework may not be an existing theory, but rather, it can be derived from the "epistemological experience, existing theory, exploratory research and thought experiments ( $p$. 44). 
In short, theories used in qualitative studies can shed light on observations and data that may be disregarded or misunderstood with the focus of a theory that is already in existence. Additionally, Maxwell singles out two ways scholars may not be able to use already established theories efficiently and these are; to be too reliant or gullible of the theory or to fail to use it enough. In their study, Anfara and Mertz (2015) concluded that in qualitative research, "the theory is not that important, it only informs methodologies and epistemologies and that they are pervasive and influential" (p. 11) to guide all the processes that a researcher goes through while preparing their preferred studies.

Because qualitative studies are descriptive and not predictive in nature, the usage of the theory in qualitative is classified into different types that are used to explain the attitudes in form of theoretical perspectives used as inductive process as a starting point for the research. Consequently, the theory is used for purposes of widely explaining the behavior and attitudes of the respondents or participants and it may be complete with variables, constructs and hypotheses. The second usage of the theory in qualitative research is with "the theoretical perspective where it is used as an outlook that shapes the questions asked in the study, that in the end informs how data collected and analyzed calls for change. The last form of use of theory in qualitative research is inductive approach" (Lancaster, 2007, p. 47).

Furthermore, Wolcott (2005) in his study examined the difference between the usage of theory in qualitative research and fieldwork. The results revealed five benefits that include; "convenience of labels, broader perspective when a study is modest in scope, connection to a larger body of data that addresses concerns with generalization, a critical perspective, and disproof by providing negative cases" (p. 12).

To sum it up, different scholars have got different views on how the theory is applied in the qualitative nature of studies, however, they use the different qualitative methodologies as well to do that. Therefore, the reviews above also show that the theoretical framework in qualitative studies are very important in the onset of the research study.

\section{The Role of the Theory in research}

The role of a theory in research is without doubt to guide researchers during the process of solving a particular problem under investigation. In addition, theories in research highlight facts that 
cannot speak for themselves. also, without a connection to other facts, it becomes hard for researchers to assess anything and therefore, with the presence of the theory, researchers can relate facts to each other.

The theory is looked at as an interrelated logical concept that is connected to the empirical facts and phenomena. Empirical research therefore works in as long as there is a theory involved to try and elaborate more on the phenomenon under study (Marrs \& Lowry 2006). Furthermore, a theory helps researchers to select the and organize facts that are relevant to consider in a study. other points that are relevant in or associated to the theory are that, it helps researchers create stories can differentiate dependent variable from the independent variable, points researchers to what they don't know about the study.

As indicated earlier on, the major role of the theory in any research study is to guide and tries to establish and distinguish facts from fiction using variables that are visible in the study.

Theories are considered to be conceptual interpretations of phenomena and their relationships. It is recognized that the theory guides practice and that research and practice are very closely linked together (Wu \& Volker 2009). In addition, Graham (2003) deduces that, theory-building in research is strong due to its problem focused nature and its likelihood to improve practice. However, before performing actual research in practice, they need to look at the existing research evidence to influence and change practice, it is vital that they first understand the theoretical and philosophical foundations of research and their related processes.

Furthermore, a theory also allows different concepts of research to talk to each other, and that allows sociology to progress. Accordingly, social facts are not ideas, they are facts and that they are observable. Facts without a certain theory backing them are and will always be meaningless, for the theory is what is charged with the role of distinguishing facts from fiction because most of the studies use deductive approaches and pick a relevant theory to the phenomenon under study. Therefore, facts alone cannot stand without the theory because they complete each other in all manners of research.

Lastly, the role of the theory can be mirrored through epistemology that relates to the theoretical view of looking for knowledge and searching for the absolute truth. It also relates to what 
relationship exists between the researcher and the phenomena they are engaged in researching as exclaimed by Denzin and Lincoln (2005).

\section{REFERENCES}

Anfara Jr, V. A., \& Mertz, N. T. (Eds.). (2014). Theoretical frameworks in qualitative research. Sage publications.

Creswell, J. D. (2017). Mindfulness interventions. Annual review of psychology, 68, 491-516.

Creswell, J. W. (2011). Controversies in mixed methods research. The Sage handbook of qualitative research, 4, 269-284.

Denzin, N. K., Lincoln, Y. S. (2011). Introduction: The discipline and practice of qualitative research. In Denzin, N. K., Lincoln, Y. S. (Eds.), The Sage handbook of qualitative research (pp. 1-20). Thousand Oaks, CA: Sage.

Flinders, D. J., Mills, G. E. (1993). Theory and concepts in qualitative research: Perspectives from the field. New York, NY: Teachers College.

Glesne, C. (2011). Becoming qualitative researchers: An introduction 4th Edition. Boston, MA.

Graham, I. W. (2003). The relationship of nursing theory to practice and research within the British context: identifying a way forward. Nursing Science Quarterly, 16(4), 346-350.

Green, H. E. (2014). Use of theoretical and conceptual frameworks in qualitative research. Nurse researcher, 21(6), 34-38.

Lancaster, G. (2007). Research methods in management. Routledge.

Marrs J-A, Lowry L W (200)6 Nursing theory and practice: connecting the dots. Nursing Science Quarterly 19:44-50.

Maxwell, J. A. (2012). Qualitative research design: An interactive approach (Vol. 41). Sage publications.

Merriam, S. B., \& Tisdell, E. J. (2015). Qualitative research: A guide to design and implementation. John Wiley \& Sons.

Saldaña, J. (2014). Thinking qualitatively: Methods of mind. Sage Publications.

Saldaña, J., \& Omasta, M. (2016). Qualitative research: Analyzing life. Sage Publications.

Taormina RJ, Gao JH., "Maslow and the motivation hierarchy: measuring satisfaction of the needs," American Journal Psychology (2013): Summer; 126(2), pp.155-77.

Wolcott, H. F. (2005). The art of fieldwork. Rowman Altamira. 
Wu, H. L., \& Volker, D. L. (2009). The use of theory in qualitative approaches to research: application in end-of-life studies. Journal of Advanced Nursing, 65(12), 2719-2732. 